\title{
Efeito antagônico de feijão-de-porco sobre Meloidogyne enterolobii em tomateiro
}

\author{
Servio Robinson Cabezas Morillo ${ }^{1}$, Gilson Soares da Silva²
}

${ }^{1}$ Mestrando em Agroecologia, Universidade Estadual do Maranhão, UEMA, CEP 65001-970, São Luís, MA; ${ }^{2}$ Departamento de Fitotecnia e Fitossanidade, Universidade Estadual do Maranhão, UEMA, CEP 65001-970, São Luís, MA.

Servio Robinson Cabezas Morillo (roca1120@yahoo.es)

Data de chegada: 25/11/2014. Aceito para publicação em: 04/05/2015.

$10.1590 / 0100-5405 / 2059$

\section{RESUMO}

Cabezas S.R.M.; Silva, G.S. Efeito antagônico de feijão-de-porco sobre Meloidogyne enterolobii em tomateiro. Summa Phytopathologica, v.41, n. 4, p.3015-310, 2015.

O presente trabalho teve como objetivo avaliar o efeito antagônico do feijão-de-porco (Canavalia ensiformis) sobre Meloidogyne enterolobii em tomateiro (Solanum lycopersicum). Foram estudados os efeitos do extrato aquoso de sementes de feijão-de-porco, nas concentrações $0,1,2,4$ e 8 g de sementes /100 mL de água sobre a eclosão e a mortalidade de juvenis (J2) in vitro. Em condições de casa-de-vegetação, avaliou-se o efeito da rega do solo, a pulverização das plantas com extrato aquoso e a incorporação de farinha de sementes ao solo, sobre os índices de galhas (IG) e de massas de ovos (MO) em raízes de tomateiro. Os resultados mostraram que todas as concentrações do extrato foram eficientes tanto na redução de eclosão como na mortalidade de juvenis de M. enterolobii, quando comparados à testemunha, também encontrouse correlação positiva entre as concentrações. Houve redução no número de galhas e de massas de ovos tanto na rega do solo como na pulverização do extrato, sendo o efeito proporcional à concentração do extrato. Com a incorporação de farinha de sementes ao solo, houve efeito fitotóxico em todos os tratamentos, não se mostrando um método adequado.

Palavras-chave: Antagonismo, Canavalia ensiformis, Nematoides, Solanum lycopersicum.

\section{ABSTRACT}

Cabezas S.R.M.; Silva, G.S. Antagonistic effect of jack bean on Meloidogyne enterolobii in tomato plants. Summa Phytopathologica, v.41, n.4, p.305-310, 2015.

The present study aimed to evaluate the antagonistic effects of jack bean (Canavalia ensiformis) on Meloidogyne enterolobii in tomato plants (Solanum lycopersicum). We studied the effects of aqueous extracts of jack bean seeds at the concentrations of $0,1,2,4$ and $8 \mathrm{~g} / 100 \mathrm{~mL}$ water on the hatching and mortality of juveniles (J2)in vitro. Under greenhouse conditions, the effect of soil irrigation, plant spraying with aqueous extracts and seed meal incorporation in the soil was evaluated on the rate of galls (IG) and the rate of egg masses (MO) in tomato roots. Results showed that all aqueous extract concentrations were efficient in reducing the hatching and the mortality of $M$. enterolobii juveniles, when compared to the control; there was also apositive correlation among concentrations. There was a reduction in the number of galls and egg masses both under soil irrigation and under aqueous extract spraying, and the effect was proportional to the extract concentration. The incorporation of seed meals in the soil led to a phytotoxic effect in all treatments, indicating that this is not an appropriate method.

Additional key-words: Antagonism, Canavalia ensiformis, Nematodes, Solanum lycopersicum.

A cultura do tomateiro (Solanum lycopersicum L) é de grande expressão econômica no cenário nacional e internacional. É a segunda olerícola mais produzida no mundo, superada apenas pela batata (7). A produção mundial foi de 138,74 milhões de toneladas, sendo que a produção brasileira foi de 3,8 milhões de toneladas e correspondendo a cerca de $2 \%$ do total mundial (12).

No Brasil, o tomate é uma das mais importantes hortaliças cultivadas e por ser muito suscetível ao ataque de pragas e patógenos, requer constantemente a adoção de diversas práticas culturais, principalmente medidas fitossanitárias, que elevam o custo de produção(1).

Dentre os fitonematoides, o gênero Meloidogyne representa o grupo de maior importância, pois são encontradas espécies que causam elevados danos à produção agrícola em nível mundial (8). Atualmente, um nematoide que representa grandes desafios aos produtores é Meloidogyne enterolobii Yang \& Eisenback (27). Esta espécie é considerada polífaga, com alto grau de disseminação e multiplicação. M. enterolobii tem o potencial de atacar plantas de tomateiro resistentes a outras espécies do mesmo gênero (5), o que torna esta espécie uma ameaça às diversas culturas de interesse econômico.

Diversos métodos são utilizados no controle dos fitonematoides (9), um método eficiente, de baixo custo e grande potencial para o produtor de tomate é o emprego de plantas antagonistas que são aquelas que contém compostos nematicidas como é o caso da espécie Canavalia ensiformis (L.), popularmente denominada feijão-de-porco. Essa planta tem sido muito estudada quanto às suas propriedades químicas e, particularmente, ao seu potencial como nematicida natural, que têm se revelado tão potente quanto alguns nematicidas comerciais. Tanto o óleo como o extrato ou o pó de suas folhas e sementes tem sido avaliados como alternativa eficiente no manejo de fitonematoides, principalmente devido sua baixa toxicidade (18). 
Também se sabe que aproximadamente $2,3 \%$ do peso das sementes dessa planta são compostos por lectinas, que são capazes de interferir na atração e migração dos nematoides em direção ao hospedeiro, impossibilitando ou reduzindo assim sua chance de iniciar o processo infectivo $(28,16,17)$.

$\mathrm{O}$ efeito das lectinas na inibição de nematoides foi observado por Gaufo et al. (10) e doses tão altas quanto $500 \mu \mathrm{g} / \mathrm{mL}$ são necessárias para a inibição do nematoide do pinheiro (Bursaphelenchus xylophilus).

Tendo em vista a importância desta hortaliça e os problemas que acarreta a utilização de produtos químicos, este trabalho teve como objetivo geral avaliar in vitro e in vivo o efeito antagônico de feijãode-porco sobre M.enterolobii em tomateiro.

\section{MATERIAL E MÉTODOS}

Os experimentos foram realizados em condições de casa-devegetação e no laboratório de Fitopatologia, do Núcleo de Biotecnologia Agronômica da Universidade Estadual do Maranhão - UEMA. (02³5'03,46’'S, 44¹2’32,14’O)

\section{Obtenção e multiplicação de Meloidogyne enterolobii}

A população de $M$. enterolobii, utilizada nos experimentos, foi obtida de goiabeiras (Psidium guajava L) infectadas no município de São Luís e mantidas em plantas de tomateiro (cv Santa Cruz Kada Gigante) em casa-de-vegetação. A identificação da espécie foi feita por meio de analise do padrão isoensimático (24). Na obtenção do inóculo para os experimentos, ovos do nematoide foram extraídos pelo método de Hussey \& Barker (11) modificado por Bonetti \& Ferraz (4).

\section{Produção de mudas de tomateiro}

Em condições de casa-de-vegetação foram produzidas as mudas de tomateiro (Solanum lycopersicum L. cv Santa Cruz Kada Gigante) utilizadas nesse trabalho, sendo a semeadura realizada em bandejas de poliestireno expandido (isopor), com 128 células, contendo solo esterilizado e substrato Plantmax ${ }^{\circledR}$ numa mistura 1:1. O transplantio para cada experimento ocorreu no período de aproximadamente 21 dias para vasos plásticos com capacidade de $2 \mathrm{~L}$, contendo solo previamente autoclavado $\left(120^{\circ} \mathrm{C} / 2 \mathrm{~h}\right)$.

\section{Obtenção dos extratos aquosos}

Os estratos foram preparados utilizando farinha das sementes moídas de feijão-de-porco nas seguintes concentrações 1,0; 2,0; 4,0; e $8,0 \mathrm{~g} / 100 \mathrm{~mL}$. de água destilada, preparados $24 \mathrm{~h}$ antes de cada experimento e mantidos no escuro à temperatura ambiente.

\section{Implantação dos experimentos}

Experimento 1: Efeito, in vitro, do extrato aquoso de sementes de feijão-de-porco sobre a eclosão de juvenis de $M$. enterolobii

Nos testes in vitro, foram utilizadas placas de acrílico de $5 \mathrm{~cm}$ de diâmetro como câmaras de eclosão, acondicionadas em uma bandeja plástica forrada com papel toalha umedecido. Foi depositado 1,0 mL da suspensão aquosa, contendo 200 ovosde M. enterolobii, calibrada com auxilio de uma lamina de Peters e $2,0 \mathrm{~mL}$ de cada extrato. Para este experimento os extratos foram filtrados em gaze, centrifugado por 10 min a $2000 \mathrm{rpm}$ e logo filtrou-se em papel de filtro. A testemunha constou apenas da suspensão de ovos em água destilada. Cada tratamento foi repetido cinco vezes. A bandeja com as placas foram mantidas por 15 dias no escuro, sendo umedecido diariamente com uma pisseta. Decorrido esse período, contou-se o número de juvenis eclodidos e de ovos remanescentes com auxilio de microscópio estereoscópio, calculando-se a porcentagem de eclosão de juvenis de acordocom a fórmula: Porcentagem de eclosão = (número de juvenis/ (número de juvenis+número de ovos))x100.

Experimento 2: Efeito, in vitro, do extrato aquoso de sementes de feijão-de-porco sobre a mortalidade de juvenis de $M$. enterolobii

Para este experimento foram utilizadas as mesmas câmaras de eclosão com as mesmas condições e os mesmos tratamentos. A testemunha constou apenas da suspensão de ovos em água destilada. Cada tratamento foi repetido cinco vezes. Os juvenis foram expostos ao extrato por $48 \mathrm{~h}$. Decorrido esse período, contou-se o número de juvenis vivos (aqueles que se movimentavam) e mortos com auxílio de microscópio estereoscópio, calculando-se a porcentagem de mortalidade de juvenis de acordo com a fórmula: Porcentagem mortalidade $=$ (número de juvenis mortos $/$ (número de juvenis mortos+número de juvenis vivos))x100.

Experimento 3: Rega do solo com extrato aquoso de sementes de feijão-de-porco em plantas de tomateiro infestadas com $M$. enterolobii

Para a montagem do experimento foram utilizados vasos de plástico com capacidade de $2 \mathrm{~L}$, onde foi colocado solo previamente autoclavado $\left(120^{\circ} \mathrm{C} / 2 \mathrm{~h}\right)$, e transplantadas mudas de tomateiro com 20 dias de idade. Em seguida, infestou-se o solo de cada vaso com uma suspensão contendo 5000 ovos e eventuais juvenis de $M$. enterolobii,calibrada com auxilio de uma lamina de Peters. No mesmo dia, foram adicionados ao solo de cada vaso, na forma de rega, $20 \mathrm{~mL}$ dos extratos aquosos nas concentrações anteriormente descritas. Os extratos foram aplicados após às 17:00 h, para evitar a degradação pela luz e temperatura alta, suspendendo-se a irrigação da tarde, para evitar lixiviação do produto aplicado. As plantas receberam adubação semanal de NPK + micronutrientes (Ouro Verde ${ }^{\circledR}$ ). O delineamento estatístico utilizado foi o inteiramente casualizado, com cinco tratamentos e sete repetições,uma planta por parcela, sendo cada parcela constituída por um vaso. As irrigações foram feitas semanalmente, durante 35 dias quando as plantas foram retiradas cuidadosamente dos vasos. Após lavagem em água corrente, o sistema radicular e a parte aérea das plantas foram pesados, as raízes foram coloridas com fucsina ácida para facilitar a contagem das galhas e massas de ovos (22).

Experimento 4: Pulverização de extrato aquoso de sementes de feijão-de-porco em plantas de tomateiro infestadas com $M$. enterolobii

Neste experimento procurou-se observar se o extrato aquoso de feijão-de-porco tem efeito sistêmico, já que na literatura não foram encontradas informações a respeito. Para este experimento também utilizou-se vasos plástico de $2 \mathrm{~L}$, contendo solo previamente autoclavado $\left(120^{\circ} \mathrm{C} / 2 \mathrm{~h}\right)$, e transplantadas mudas de tomateiro com 20 dias de idade. Em seguida, infestou-se o solo de cada vaso com uma suspensão contendo 4000 ovos e eventuais juvenis de M. enterolobii. No mesmo dia, fez-se a pulverização dos extratos nas concentrações anteriormente descritas, com um pulverizador manual, aplicando-se o extrato nas superfícies abaxial e adaxial das folhas de tomateiro, até o ponto de escorrimento. As pulverizações foram feitas semanalmente durante 35 dias.Cada vaso foi protegido por um saco plástico para evitar que o extrato aplicado na parte aérea atingisse o solo e interferisse nos resultados (3). Neste experimento, foram aplicados os mesmos tratamentos que no anterior, mais o tratamento controle (água destilada), após $24 \mathrm{~h}$ de preparo. O extrato foi aplicado após as 17:00 h 
e suspendeu-se a irrigação da tarde, para que o princípio ativo pudesse permanecer mais tempo sobre a folha, com 35 dias as plantas foram retiradas para a contagem de galhas e massas de ovos descritas no experimento anterior, a adubação e o delineamento estatístico utilizado foram igual que o experimento 3 .

Experimento 5: Incorporação de farinha de sementes de feijãode-porco em solo infestado com M. enterolobii

Neste experimento, utilizou-se vasos de $2 \mathrm{~L}$ de capacidade onde se misturou solo, previamente autoclavado $\left(120^{\circ} \mathrm{C} / 2 \mathrm{~h}\right)$, com farinha de sementes feijão-de-porco, nas dosagens de 8,0;10,0 e 12,0 g/kg de solo, Plantas mantidas em vasos sem a incorporação da farinha de sementes trituradas de feijão de porco serviram como testemunhas. Em seguida, cada vaso recebeu 4.000 ovos e eventuais juvenis de M. enterolobii, extraídos pelo método de Hussey \& Barker (11). Utilizou-se mudas de tomateiro com 21 dias de idade, a adubação foi feita da mesma forma que o experimento 3 e o delineamento estatístico adotado foi inteiramente casualizado, com quatro tratamentos e cinco repetições.

\section{RESULTADOS E DISCUSSÃO}

Experimento 1: Efeito, in vitro, do extrato aquoso de sementes de feijão-de-porco sobre a eclosão de juvenis de $M$. enterolobii

Foi possível observar que todos os tratamentos tiveram efeito sobre a eclosão de juvenis de M. enterolobii, quando comparados à testemunha (Figura 1). A taxa de eclosão para o tratamento com maior concentração (8g/100 mL de água) foi de 2,1\%, o que representou redução na eclosão dos juvenis de $96,6 \%$, em relação à testemunha. A baixa taxa de eclosão dos juvenis comprovou que o extrato de sementes de feijão-de-porco teve efeito tóxico sobre os ovos de $M$. enterolobii. O uso de extratos e/ou de sementes de plantas para diminuição da eclosão de juvenis de alguns nematoides já foi testado por outros pesquisadores $(2,6,17,19)$.

Experimento 2: Efeito, in vitro, do extrato aquoso de sementes de feijão-de-porco sobre a mortalidade de juvenis de $M$. enterolobii

Neste experimento comprovou-se também o efeito tóxico do extrato de sementes de feijão-de-porco sobre a mortalidade dos juvenis de M. enterolobii. A Figura 2 mostra que estatisticamente o tratamento $1 \mathrm{~g} / 100 \mathrm{~mL}$ foi igual que à testemunha, e os demais tratamentos

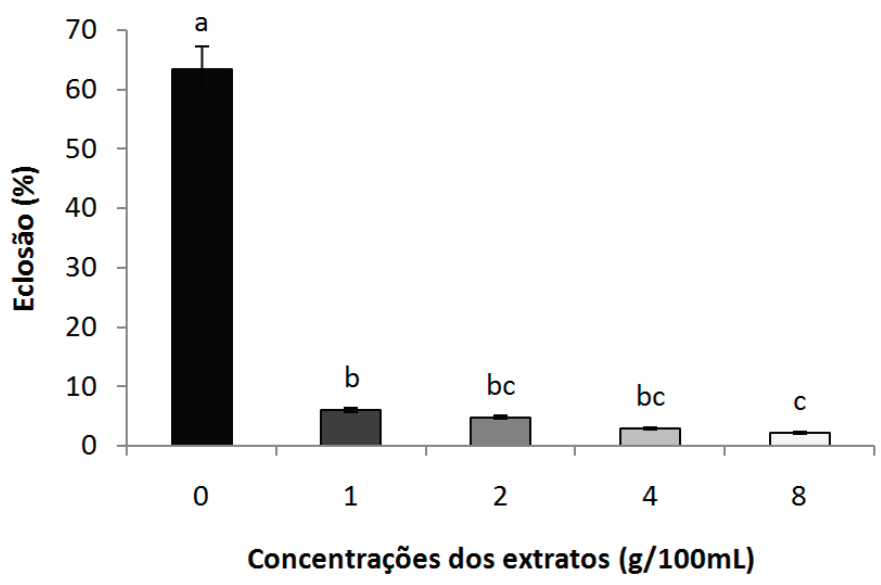

Figura 1: Porcentagem de eclosão de juvenis de Meloidogyne enterolobii sob diferentes concentrações do extrato de feijão-de-porco. Médias seguidas pela mesma letra não diferem estatisticamente entre si, pelo o teste de Tukey a 5\% de probabilidade. tiveram diferença estatística com relação à testemunha, sendo que a maior concentração $(8 \mathrm{~g} / 100 \mathrm{~mL}$ de água) levou à morte $100 \%$ dos juvenis desse nematoide. Esses resultados comprovam que o extrato de sementes de feijão-de-porco teve efeito nematostático sobre os juvenis de M. enterolobii. Segundo Lerner \& Raikhel (14) às lectinas se ligam à quitina (componente principal da cutícula dos nematoides) e a formação do complexo provoca um efeito deletério. Em consequência, o nematoide pode ter crescimento retardado ou não atingir a face adulta (20). Os experimentos 1 e 2 mostraram que também há uma correlação positiva entre as diferentes concentrações estudadas. Assim, quanto maior a concentração, melhor a eficiência na diminuição de eclosão de juvenis e na mortalidade.

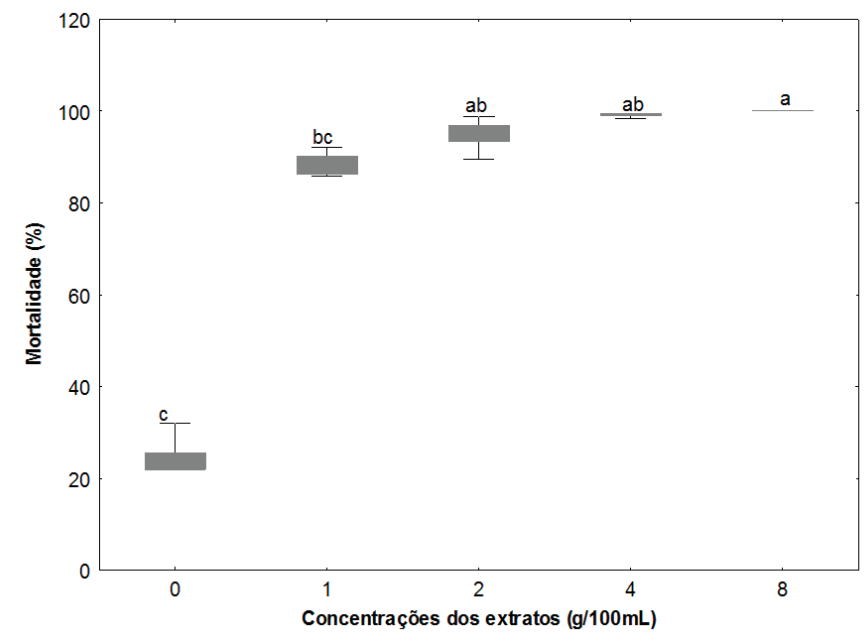

Figura 2. Porcentagem de mortalidade de juvenis de Meloidogyne enterolobii. sob efeito de diferentes concentrações do efeito aquoso de feijão-de-porco. Letras iguais não diferem estatisticamente entre as médias dos gruposde acordo com a ANOVA não paramétrica de Kruskal-Wallis seguida do teste de Tukey a $5 \%$ de probabilidade.

Experimento 3: Rega do solo com extrato aquoso de sementes de feijão-de-porco em plantas de tomateiro infestadas com $M$. enterolobii

Neste experimento avaliou-se onúmero de galhas (NG) e massas de ovos (MO) para observar se os tratamentos apresentaram efeito antagônico sobre $M$. enterolobii. Também foram coletados dados de pesos das raízes e peso da parte aérea para ver se o produto aplicado interfere no desenvolvimento do tomateiro. Os resultados apresentados na Tabela 1 mostram que na maior concentração, o NG (número de galhas) e MO (massas de ovos) diminuiu consideravelmente, até dois graus segundo a escala de Taylor \& Sasser (25), no caso das MO o tratamento com maior concentração reduziu até $84,7 \%$ (Figura 3 ).

Tabela 1. Efeito da irrigação no solo com extratos aquosos de sementes de feijão-de-porco no controle de Meloidogyne enterolobii em tomateiro.

\begin{tabular}{ccccc}
\hline $\begin{array}{c}\text { Tratamentos } \\
\text { g/100 } \mathbf{~} \mathbf{1} \text {. de água }\end{array}$ & $\begin{array}{c}\text { Número } \\
\text { de galhas }\end{array}$ & IG* $^{*}$ & $\begin{array}{c}\text { Massa } \\
\text { de ovos }\end{array}$ & IMO* \\
\hline 0 (testemunha) & 100,00 & 5 & 88,71 & 4 \\
1 & 52,57 & 4 & 31,86 & 4 \\
2 & 62,43 & 4 & 52,00 & 4 \\
4 & 41,71 & 4 & 36,57 & 4 \\
8 & 26,57 & 3 & 13,57 & 3 \\
\hline CV\% & 76,26 & 40,19 & 90,67 & 43,19 \\
\hline
\end{tabular}

*IG=índice de galhas; $\mathrm{IMO}=$ índice de massas de ovos. 


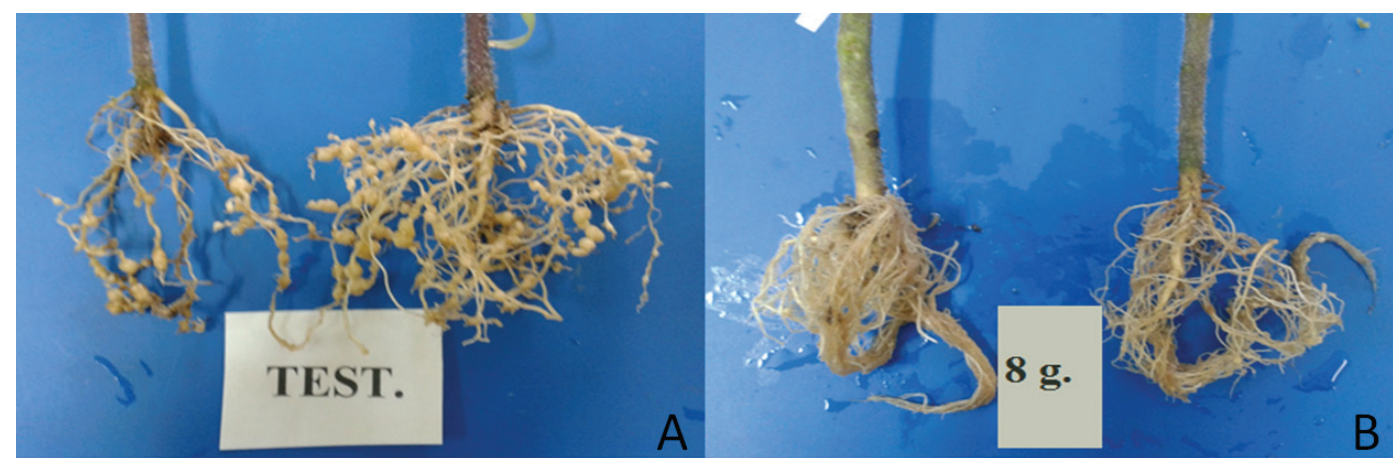

Figura 3. Sistemas radiculares de tomateiros cultivados em solo irrigados com extratos aquosos de feijão de porco. $\mathrm{A}=$ testemunha; $\mathrm{B}=$ tratado com $8 \mathrm{~g}$ de pó de sementes de feijão-de-porco.

Marban-Mendonza et al. (16) em seus experimentos in vitro demonstraram que as lectinas estão associadas ao bloqueio de quimiorreceptores dos nematóides, o qual dificulta tanto a mobilidade quanto a localização das plantas por parte dos parasitas. Segundo Jonsson (13) existem dois tipos de receptores: os quimiorreceptores, ligados à membrana do neurônio, e os receptores de superfície, ambos contendo carboidratos. A ligação do químico atrativo à terminação do carboidrato do receptor da glicoproteina resulta em interação normal de quimiotactismo, podendo essa interação ser bloqueada pela ação de lectinas que se ligam ao terminal do carboidrato ou inibir completamente o quimiotactismo pela ação de enzimas hidrolíticas.

As análises comprovaram que não houve diferenças estatísticas quanto ao crescimento da parte aérea (Figura 4) e no peso das raízes (Figura 5), ou seja, que o produto testado não tem influência negativa no desenvolvimento da planta, fato considerado positivo já que o extrato diminui o NG e MO, mas não apresenta problemas de toxicidade nas plantas de tomateiro.

Experimento 4: Pulverização de extrato aquoso de sementes de feijão-de-porco em plantas de tomateiro infestadas com $M$. enterolobii

Neste experimento avaliou-se as mesmas variáveis do experimento

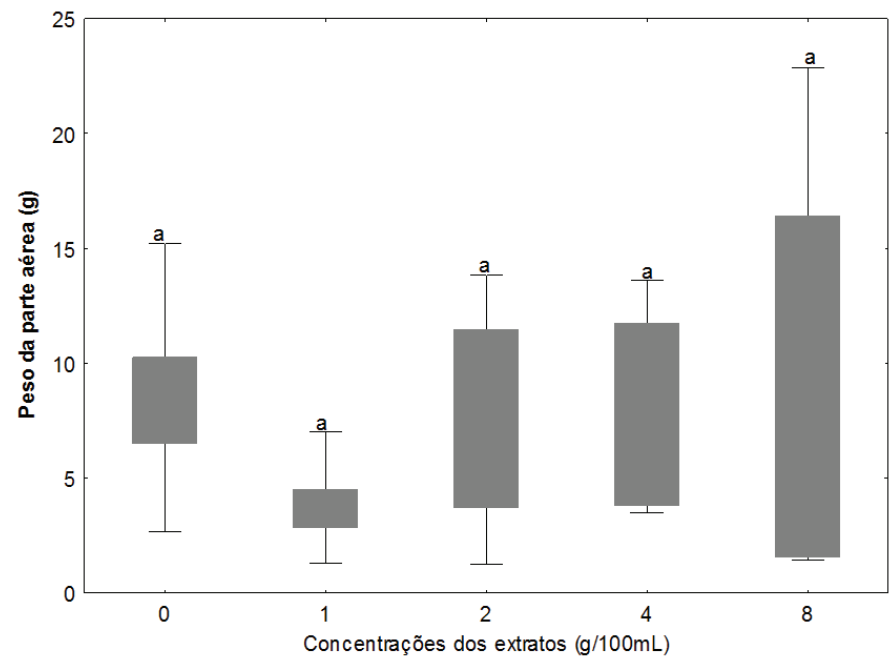

Figura 4. Peso da parte aérea dos tomateiros irrigados com extrato aquoso de feijão-de-porco. Letras iguais não diferem estatisticamente entre as médias dos grupos de acordo com a ANOVA não paramétrica de Kruskal-Wallis seguida do teste de Tukey a $5 \%$ de probabilidade. anterior. De acordo com a Tabela 2, os dados mostraram uma pequena redução no NG e MO o que evidencia um fraco efeito do produto quando aplicado na forma de pulverização.

Segundo Wallace (26) a orientação e a migração dos fitonematóides para raízes de plantas dependem de vários fatores, dentre os quais a natureza dos exsudatos radiculares. A pulverização deste extrato poderia ter modificado a constituição química dos exsudatos da planta e com isso afetar a recepção dos estímulos quimioreceptores dos juvenis. Estes efeitos mínimos poderiam ser devido ao modo de aplicação já que o mesmo produto utilizado diretamente no solo, na forma de rega, teve melhores resultados, também pode ser devido a forma do preparo do extrato, como observaram Scramin et al. (21) que a atividade nematicida de algumas espécies depende do solvente utilizado na extração de seus produtos.

Também determinou-se o peso da parte aérea e peso da raiz a fim de testar o efeito dos extratos aplicados nas plantas de tomateiro, segundo os resultados a pulverização deste extrato não diferiu estatisticamente quanto ao peso da parte aérea (Figura 6). Entretanto houve uma diferença estatística quanto ao peso da raiz, no qual o tratamento controle diferiu dos demais, apresentando os valores mais altos (Figura 7).

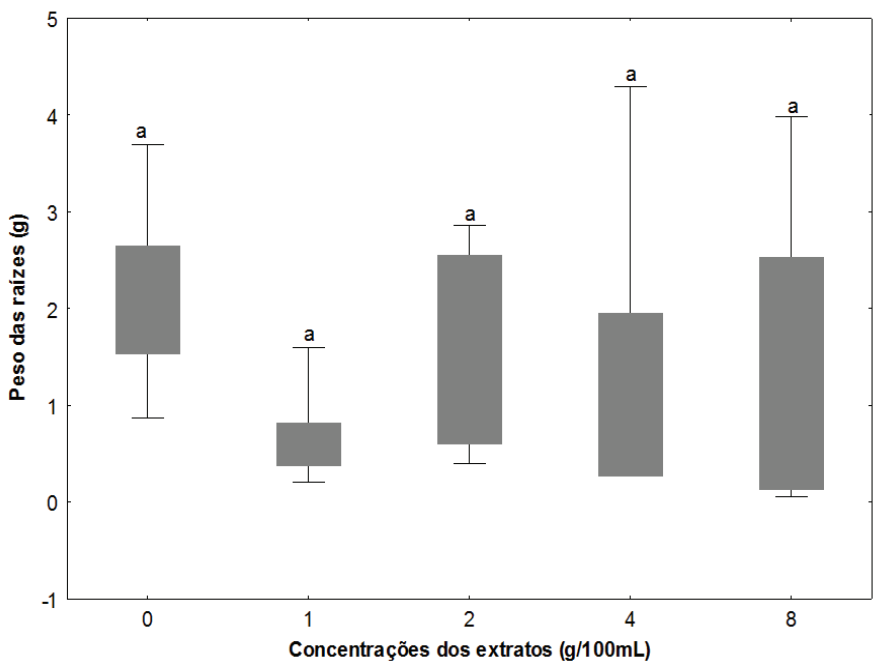

Figura 5. Peso das raízes dos tomateiros irrigados com extratos aquosos de feijão-de-porco. Letras iguais não diferem estatisticamente entre as médias dos grupos de acordo com a ANOVA não paramétrica de Kruskal-Wallis seguida do teste de Tukey a 5\% de probabilidade. 
Tabela 2. Efeito da pulverização com extratos aquosos de sementes de feijãode-porco no controle de Meloidogyne enterolobii em tomateiro.

\begin{tabular}{ccccc}
\hline $\begin{array}{c}\text { Tratamentos } \\
\text { g/100 mL. de água }\end{array}$ & $\begin{array}{c}\text { Número } \\
\text { de galhas }\end{array}$ & IG $^{*}$ & $\begin{array}{c}\text { Massa } \\
\text { de Ovos }\end{array}$ & IMO* \\
\hline 0 (testemunha) & 100,0 & 5 & 100,0 & 5 \\
1 & 100,0 & 5 & 96,4 & 4 \\
2 & 100,0 & 5 & 90,7 & 4 \\
4 & 90,0 & 4 & 88,3 & 4 \\
8 & 90,1 & 4 & 71,7 & 4 \\
CV\% & 14,38 & 4,85 & 23,84 & 8,41 \\
\hline
\end{tabular}

*IG=índice de galhas; $\mathrm{IMO}=$ índice de massas de ovos.

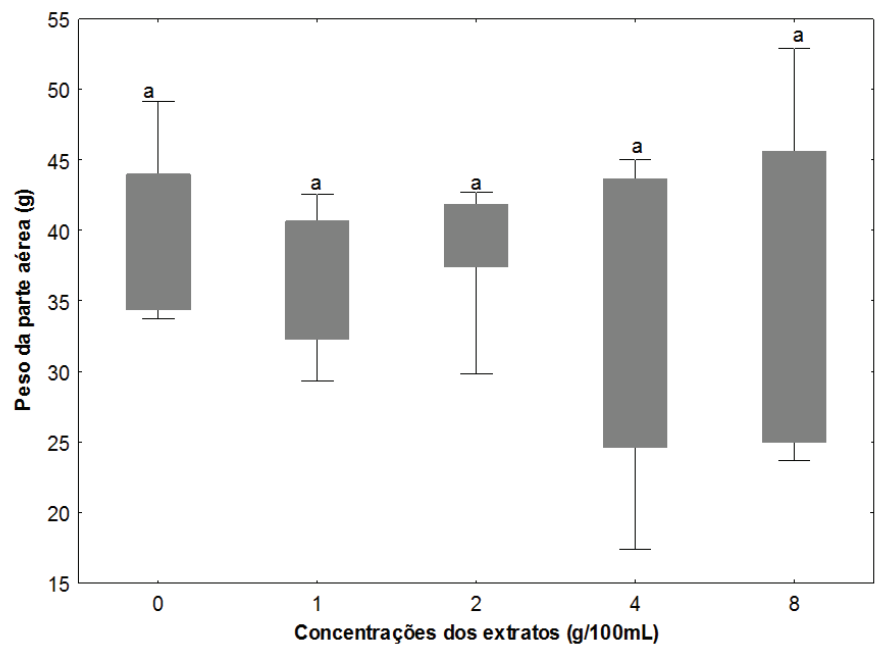

Figura 6. Peso da parte aérea dos tomateiros pulverizados com extratos aquosos de feijão-de-porco.Letras iguais não diferem estatisticamente entre as médias dos gruposde acordo com a ANOVA não paramétrica de Kruskal-Wallis seguida do teste de Tukey ao nível de $5 \%$ de probabilidade.

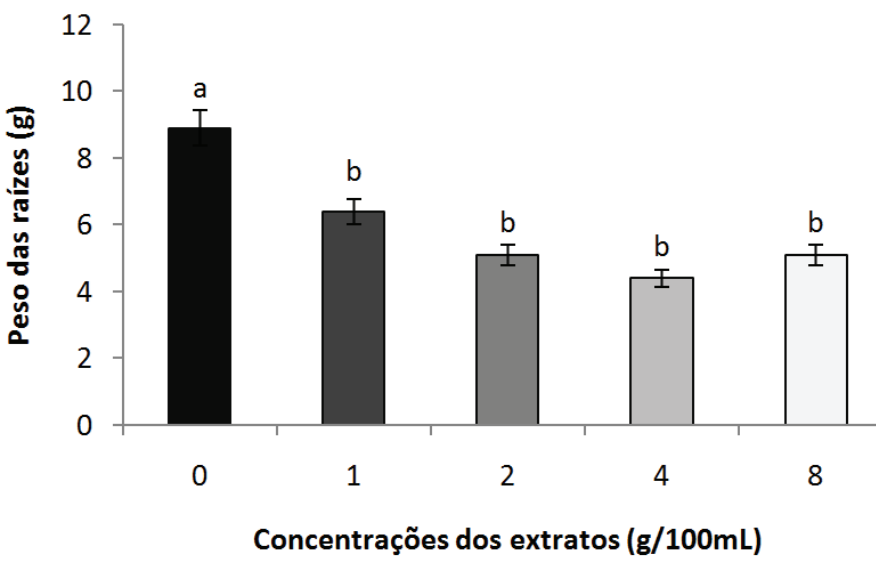

Figura 7. Peso das raízes dos tomateiros pulverizados com extratos aquosos de feijão-de-porco.As médias com a mesma letra não diferem estatisticamente entre si pelo teste de Tukey $(\mathrm{p}<0,05)$.

Experimento 5: Incorporação de farinha de sementes de feijãode-porco em solo infestado $\operatorname{com} M$. enterolobii

Neste experimento comprovou-se que a utilização de farinha de sementes de feijão-de-porco foi tóxico ao tomateiro. No tratamento com maior concentração $(12,0$ g.) todas as plantas morreram após sete dias, no tratamento com (10,0 g. $) 80 \%$ das plantas morreram e no tratamento com (8,0 g.) 40\% das plantas morreram. Também observouse que as plantas que sobreviveram tinham um desenvolvimento menor quanto comparadas com o tratamento controle. As poucas plantas que sobreviveram não desenvolveram as raízes e tampouco houve um desenvolvimento na parte aérea.Isso concorda com os resultados de Lopes et al. (15) que observaram uma redução de até 9\% quando incorporou as folhas de feijão-de-porco ao solo. Também não houve formação de galhas nas raízes, isso pode ser pelo efeito da farinha que interferiu na eclosão dos juvenis e no efeito nematostático. Embora o produto tenha sido positivo no controle de $M$. enterolobii também tem o problema da toxicidade nas plantas de tomateiro. Alguns estudos, como o de Mendes (18), comprovaram a presença de substâncias herbicidas no controle de algumas plantas daninhas, confirmando esta hipótese. É necessário a realização de experimentos mais detalhados para ver qual é a substância que afeta o desenvolvimento do tomateiro já que nos experimentos anteriores o produto testado não interferiu. Outro experimento que contradiz esta hipótese é o trabalho de Silva et al. (23) que incorporaram farinha de sementes de feijão-de-porco no solo para o controle de $M$. incógnita e teve bons resultados sem problemas de toxicidade. Mendes (18), também afirma que o extrato de feijão-de-porco não afeta o desenvolvimento da soja e que só teve efeito fitotóxico nas duas plantas daninhas que ele testou (Commelina benghalensis e Ipomoea grandifolia).

Com base nestes resultados pode-se concluir que a utilização de extratos à base de feijão-de-porco na forma de rega no solo é efetivo no controle de Meloidogyne enterolobii.

\section{AGRADECIMENTOS}

Agradecemos ao Programa de Mestrado em Agroecologia da Universidade Estadual do Maranhão e a CAPES pela concessão da bolsa de estudo.

\section{REFERÊNCIAS BIBLIOGRÁFICAS}

1. Anvisa, Agência Nacional de Vigilância Sanitária, 2014. Disponível em: $<$ http://cup-id.com/lista-da-anvisa-dos-alimentos-com-maior-nivel-de-contaminacao/>. Acesso em: 4 jun. 2014.

2. Azam, M.F.; Mehmood, R.K.; Shamim, A. Effect of plant extract of some members of Asteraceae on hatching and mortality of root-knot nematode, Meloidogyne incognita. Bionotes, Aligarh, v.3, n.1, p. 9-10, 2001

3. Bala, S.K.; SukuL, N.C. Systemic nematicidal effect of eugenol. Nematropica, West Bengal, v.17, p.219-222, 1987.

4. Bonetti, J.I.S.; Ferraz, S. Modificações do método de Hussey \& Barker para extração de ovos de Meloidogyne exigua em raízes de cafeeiro. Fitopatologia Brasileira, Brasília, DF, v.6, n.3, p.553, 1981.

5. Carneiro, R.M.D.G.; Almeida, M.R.A.; Braga, R.S.; Almeida, C.A.; Gloria, R. Primeiro registro de Meloidogyne mayaguensis parasitando plantas de tomate e pimentão resistentes à meloidoginose no Estado de São Paulo. Nematologia Brasileira, Piracicaba, v.30, n.1, p.81-86, 2006.

6. Dias, C.R.; Schwan, A.V.; Ezequiel, D.P.; Sarmento, M.C.; Ferraz, S Efeito de extratos aquosos de plantas medicinais na sobrevivência de juvenis de Meloidogyne incognita. Nematologia Brasileira, Viçosa, v.24, n.2, p.203-210, 2000.

7. FAO, Organização das Nações Unidas para Agricultura e Alimentação, 2012. Disponível em: <http://faostat.fao.org/site/339/default.aspx>. Acesso em: 23 Dec. 2013.

8. Ferraz, L.C.C.B. As meloidoginoses da soja: passado, presente e futuro. In. Silva, J.F.V.; Mazaffera, P.; Carneiro, R.G.; Asmus, G.L.; Ferraz, L.C.C.B. Relações parasito-hospedeiro nas meloidoginoses da soja. Londrina, Embrapa Soja/Sociedade de Nematologia, 2001, cap.1, p.15-38.

9. Ferraz, S.; Freitas, L.G.; Lopes, E.A.; Dias-Arieta, C.R. Manejo sustentável 
de nematoides. Viçosa, MG: UFV, 2010. 304p.

10. Gaofu, Q.; Shiquing, M.; Fayin, Z.; Zhiniu, Y.; Xiuyun, Z. In vitro assessment of plant lectins with anti-pinwood nematode activity. Journal of Invertebrate Pathology, Maryland Heights, v.98, p.40-45, 2008.

11. Hussey, R.S.; Barker, K.R.A. Comparison of methods for collecting inocula of Meloidogyne spp., Including a new technique. Plant Disease Reporter, St. Paul, v.57, n.12, p.1025-1028, 1973.

12. IBGE. Tomate: productividade de 2012. Disponível em: <http://www. sidra.ibge.gov.br. >. Acesso em: 23 de feb 2014.

13. Jonsson, H. B. Receptors and recognition in nematodes. In: Veech, J.A. \& Dickson, D.W. Vistas on nematology, Hyattsville: Society of Nematologists, 1987. Cap.22, p.153-158.

14. Lerner, D.R.; Raikhel, N.V. The gene for stinging nettle lectin (Urticadioica Agglutinin) encodes both a lectin and a chitinase. The Journal of Biological Chemistry, East Lansing, v.267, p.11085-11091,1992.

15. Lopes, E.A.; Ferraz, S.; Ferreira, P.A.; Freitas, L.G.; Gardiano, C.G.; Dhingra, O.D.; Dallemole-Giaretta, R. Efeito da incorporação da parte aérea de quatro espécies vegetais sobre Meloidogyne javanica, Nematologia Brasileira, Piracicaba, v.32, n.1, p.76-80, 2008.

16. Marban-Mendoza, N.; Yejaprakash, A.; Janson, H.B.; Damon Jr. R.A.; Zuckerman, B.M. Control of root-knot nematodes on tomato by lectins. Jornal of Nematology, College Park, v.19, n.3, p.331-335, 1987.

17. Marban-Mendoza, N.; Diklow, M.B.; Zuckerman, B.M. Control of Meloidogyne incognita on tomato by two leguminous plants. Fundamental and Applied Nematology, Turrialba, v.15, p.87-108, 1992.

18. Mendes, I.S. Avaliação de extratos das folhas e sementes de feijão-de-porco (Canavalia ensiformis) como bioerbicidas pós-emergentes e identificação de aleloquímicos via cromatográfica liquida de alta eficiência (HPLC). 2011. Dissertação (Mestrado em Química Analitica) - Instituto de Quimica de São Carlos, Universidade de São Paulo, São Carlos.
19. Neves, W.S.; Freitas, L.G.; Lopes, E.A.; Coutinho, M.M.; Dallemole-Giaretta, R.; Ferraz, S. Efeito, in vitro, do extrato de sementes de mamão sobre a eclosão e juvenis de Meloidogyne spp. Revista Trópica-Ciências Agrárias e Biológicas, Viçosa, MG, v.2, n.3, p.9, 2008.

20. Peumans, W.J.; VanDamme, E.J. Lectins as plant defense proteins. Plant Physiology, Leuven, Belgium, v.109, n.2, p.347-352, 1995.

21. Scramin, S.; Silva, H.P.; Fernandes, L.M.S.; Yhan, C.A. Avaliação biológica de extratos de 14 especies vegetais sobre Meloidogyne incognita raza 1. Nematologia Brasileira, Campinas, v.11, p.89-101, 1987.

22. Silva, G.S.; Santos, J.M.; Ferraz, S. Novo método de coloração de ootecas de Meloidogyne sp. Nematologia Brasileira, Dourados, MS, v.12, p.6-7, 1988.

23. Silva, G.S.; Souza, I.M.R.; Cutrim, F.A. Efeito da incorporação de sementes trituradas de feijão de porco ao solo sobre o parasitismo de Meloidogyne incógnita em tomateiro. Fitopatologia Brasileira, Brasilia, v.27, n.4, p.412-413, 2002.

24. Silva, G.S.; Pereira, A.L.; Araújo, J.R.G.; Carneiro, R.M.D.G. Ocorrência de Meloidogyne mayaguensis em Psidium guajava no Estado de Maranhão. Nematologia Brasileira, Campinas, v.32, n.3, p.242243, 2008.

25. Taylor, A.L.; Sasser, J.N. Biology, identification and Control of Rootknot nematodes (Meloidogyne Species). Departament of Plant Pathology - North Carolina State University Graphics, Raleigh, 1978.111p.

26. Wallace, H.R. The biology of plant parasitic nematodes. London: Edward Arnold Publishers, 1963. 280p.

27. Yang, B.; Eisenback, J.D. Meloidogyne enterolobii sp. (Meloidogynidae) a root-knot nematode parasiting pacara earpod tree in China. Journal of Nematology, College Park, v.15, n.3, p.381-391, 1983.

28. Zuckerman, B.M. Hypotheses and possibilities of intervention in nematode chemoresponses. Jornal of Nematology, Collage Park, v. 15, n.2, p.173-182, 1983. 